BJHS: Themes 4: 245-271, 2019. C British Society for the History of Science 2019. This is an Open Access article, distributed under the terms of the Creative Commons Attribution licence (http://creativecommons.org/licenses/by/4.0/), which permits unrestricted re-use, distribution, and reproduction in any medium, provided the original work is properly cited.

doi:10.1017/bjt.2019.6 First published online 7 August 2019

\title{
The museum in the lab: historical practice in the experimental sciences at Cambridge, 1874-1936
}

\author{
BORIS JARDINE*
}

\begin{abstract}
This paper explores the hoarding, collecting and occasional display of old apparatus in new laboratories. The first section uses a 1936 exhibition of Cambridge's scientific relics as a jumping-off point to survey the range of historical practices in the various Cambridge laboratories. This panoramic approach is intended to show the variety and complexity of pasts that scientists had used material to conjure in the years prior to the exhibition. Commerce and commemoration emerge as two key themes. The second part turns to the Cavendish Laboratory (experimental physics) to explore the highly specific senses of time and memorialization at play in the early years of the laboratory (c.1874-1910), and the way these were transformed over the subsequent generations leading up to the 1936 moment. The key figure here is James Clerk Maxwell, whose turn to history involved a mix of antiquarianism and modernism. The paper concludes with an attempt to characterize the meanings and significances of 'the museum in the lab'. This phenomenon ought to be understood in terms of the wide range of 'collections' present in laboratory spaces.
\end{abstract}

When men wish to have things remembered, they set up monuments, and write inscriptions and books, - they draw pictures and take photographs, - in order that these material things may help them, in time to come, to call up the thought of that which they were intended to commemorate.

James Clerk Maxwell, 'Psychophysik' $(1878)^{1}$

\footnotetext{
* Department of History and Philosophy of Science, University of Cambridge, Free School Lane, Cambridge, CB2 3RH, UK. Email: bj210@cam.ac.uk.

This work was supported by the Isaac Newton Trust (grant number RG81914) and the Leverhulme Trust (grant number RG79693).

I am especially grateful to Jenny Bangham and Emma Kowal for their productive suggestions and comments on all aspects of museum and laboratory life, and for being such wonderful collaborators on the broader How Collections End project. A version of this paper was presented at the Humboldt University, Berlin, in June 2017, and I would like to thank Anke te Heesen, Mathias Grote and their colleagues for a highly stimulating discussion. Contributors to the How Collections End workshop in Cambridge, October 2017, also gave valuable feedback, notably Alison Boyle, Dahlia Porter and Simon Schaffer. Isobel Falconer has provided invaluable insights into the history of historical practice at the Cavendish. Many thanks to the $B J H S$ editorial team and the anonymous referees for their assistance and insightful comments and corrections.

1 James Clerk Maxwell, 'Psychophysik', first printed in Lewis Campbell and William Garnett, The Life of James Clerk Maxwell: With a Selection from His Correspondence and Occasional Writings and a Sketch of His Contributions to Science, London: MacMillan and Co., 1882, pp. 452-463, 454.
} 
When the University of Cambridge's Cavendish Laboratory of experimental physics was opened in June 1874, it must have presented a stark vision of the future of science to the gathered dignitaries. ${ }^{2}$ The building itself was grand enough, especially its neo-Gothic frontage, impressive carved wooden gates and generous south-facing windows. ${ }^{3}$ But the rooms themselves were surprisingly empty of experimental apparatus. In spite of the long lists of desiderata that the first director, James Clerk Maxwell, had drawn up in preparation, by the time the doors were opened, a laboratory of twenty or so rooms was populated with barely a hundred separate pieces of equipment, many of which were old, or borrowed, or both. ${ }^{4}$

In response to this situation the chief benefactor of the laboratory, William Cavendish, 7th Duke of Devonshire, offered to pay for new instruments, and Maxwell drew up a list of items to be supplied by the firms of Elliott Brothers, William Ladd, Ludwig Oertling and Sir Joseph Whitworth \& Co. ${ }^{5}$ By April 1875, when Maxwell prepared his first report to the university on the activities of the laboratory, he could list an extensive array of apparatus. ${ }^{6}$ Amidst this quickly growing collection, however, the following entries stand out:

Presented by the late C. Babbage, F.R.S./Thermometer found by Antinori in the repositories of the Accademia del Cimento.

Presented by Mrs Faraday/Lines of Magnetic Force prepared by Faraday.

Presented by M. Tresca/Model of the Wave-Surface of Fresnel.

These objects were clearly not intended to further the scientific researches of the Cavendish, but nor were they simply curios to be placed on a desk or hidden in a cupboard. Maxwell's second report, the following year, showed that the practice of acquiring historic objects was in fact an important part of the life of the laboratory. A list of some ninety instruments was included alongside the following note:

A large collection of instruments, apparatus and fittings, has been presented to the University by H.W. Elphinstone, M.A., of Trinity College. Most of these belonged to the celebrated William Hyde Wollaston, M.D., of Gonville and Caius College, and many of them are of historical interest. $^{8}$

2 A substantial account of the laboratory and the opening ceremony was published in [anon.], Nature (1874) 10, pp. 139-142.

3 On the influences behind the style of the building and the importance of aesthetics see Simon Schaffer, 'Physics laboratories and the Victorian country house', in Crosbie Smith and Jon Agar (eds.), Making Space for Science: Territorial Themes in the Shaping of Knowledge, Oxford: Oxford University Press, 1982, pp. 22-24.

4 For Maxwell's various lists of equipment, desired and then acquired, see Peter M. Harman (ed.), The Scientific Letters and Papers of James Clerk Maxwell, vol. 2: 1862-1873, Cambridge: Cambridge University Press, 1995, pp. 631-632, 868-875; and vol. 3: 1873-1879, Cambridge: Cambridge University Press, 2002, pp. 64-65, 86-88, 209-215, 337-343.

5 Harman, op. cit. (4), vol. 3, pp. 85-88.

6 Harman, op. cit. (4), vol. 3, pp. 208-215.

7 Harman, op. cit. (4), vol. 3, pp. 213-214.

8 Harman, op. cit. (4), vol. 3, pp. 337-343. 
If this establishes the scale of antiquarianism in the early years of the Cavendish, we need only turn to Maxwell's published and unpublished writings for confirmation of the underlying desire and intentionality. The 'Thermometer found by Antinori in the repositories of the Accademia del Cimento', for example, was in fact a seventeenth-century instrument that Maxwell had first heard of through his friend Peter Guthrie Tait. After seeing this instrument Maxwell had written with unbridled enthusiasm to Tait:

Can you tell me the tale of the Florentine thermometers, one of which is in your Apparatus room having glass beads for degrees? Who made them? at what date? Were any ancient observations made with them which have been translated into modern degrees since the discovery of the instrument. When were they lost? Who discovered them again \& when? Who wished they had been discovered? Who gave one to the Edin[burgh] Nat Phil. Is there anything in print about it? Information sent to [me] will receive due attention. ${ }^{9}$

With remarkable speed Tait's answers to these queries were incorporated by Maxwell into the chapter on thermometry of his 1871 textbook Theory of Heat. He also tracked down one of the Florentine thermometers that had been presented to Charles Babbage: this was the instrument recorded in the report of 1875 , which now took pride of place in the Cavendish's growing historical collections. ${ }^{10}$

Within a year of its opening, then, the Cavendish Laboratory was transformed from a sparsely populated lab to a space full of apparatus, much of which was of antiquarian interest rather than experimental utility. In addition to the thermometer, many other important historical objects were stored in the instrument room on the first floor, alongside teaching models and modern experimental apparatus. ${ }^{11}$

Perhaps surprisingly, this turn to history was common among the new laboratories that rose up in the centre of Cambridge at the end of the nineteenth and the beginning of the twentieth centuries. ${ }^{12}$ In addition to Maxwell's idiosyncratic approach to the past - explored at length below - other modes of collecting were more systematic and were tied to the construction of institutional identity. Some laboratories collected or preserved objects in order to celebrate their great achievements or to commemorate important figures; others consolidated certain styles of instrumental work through the tracing of the 'evolution' of a piece of commercial apparatus in use or (even better) developed in the laboratory.

The contexts for this phenomenon were institutional and spatial. The Cavendish Laboratory was situated on a site first developed for scientific museums, and it developed both within and against the framework of the 'museological' sciences. ${ }^{13}$ Cambridge's

9 Harman, op. cit. (4), vol. 2, p. 645; for Maxwell's further researches see p. 648.

10 James Clerk Maxwell, Theory of Heat, London: Longmans, Green, and Co., 1871, p. 34.

11 For plans of the newly opened Cavendish see [anon.], op. cit. (2), pp. 140-141.

12 On the 'rise' of these laboratories see Romualdas Sviedrys, 'The rise of physical science at Victorian Cambridge', Historical Studies in the Physical Sciences (1970) 2, pp. 127-151; Sviedrys, 'The rise of physics laboratories in Britain', Historical Studies in the Physical Sciences (1976) 7, pp. 405-436. For institutional context see Christopher N.L. Brooke, A History of the University of Cambridge, vol. 4: 1870-1990, Cambridge: Cambridge University Press, 1993, Chapters 6, 15.

13 John V. Pickstone, 'Museological science? The place of the analytical/comparative in nineteenth-century science, technology and medicine', History of Science (1994) 32, pp. 111-138. 
'New Museums Site' was the first large-scale space used by the university for scientific lectures, collections and laboratories; the main suite of museums was opened in 1865. ${ }^{14}$ After the Cavendish, further laboratories were built on the site well into the twentieth century. ${ }^{15}$ However, as others have documented, the museological sciences not only persisted through the laboratory revolution, but they were also considered equally significant and even sometimes inhabited the same spaces. ${ }^{16}$ Bruno Strasser, for example, writes that in the early twentieth century 'the natural historical way of knowing, based on collecting, comparing, and computing, came to be practiced in the laboratory'. ${ }^{17}$ There is plenty of evidence to support Strasser's thesis in Cambridge. The later Downing Site - which was developed in the early twentieth century specifically in order to cater for new laboratories of botany, agricultural science, parasitology and cryogenics - was ultimately home to more scientific museums than the older New Museums Site. Collections of historical apparatus in laboratories are, of course, distinct from the specific practices of natural-history collections. But, as I argue below, there is in fact a connection between museological science and the historicity of scientific objects.

One distinctive feature of collections of old apparatus in new laboratories - a feature that separates them from our modern sense of a 'museum' - is that they did not last. ${ }^{18}$ They were not based on 'best practice' or conservation standards, had little public function and oriented themselves to the ever-present rather than the perpetual future. ${ }^{19}$ Endings are therefore multiple and highly contingent. The relationship between materiality and historical understanding is the direct inverse of the relationship between materiality and scientific knowledge. The latter involves the production of apparently stable

14 On the New Museums Site see Robert Willis and John Willis Clark, The Architectural History of the University of Cambridge and of the Colleges of Cambridge and Eton, vol. 3, Cambridge: Cambridge University Press, 1886, Chapter 2.

15 For an early (but still unsurpassed) account of this process see Arthur E. Shipley, 'J.': A Memoir of John Willis Clark, London: Smith, Elder \& Co., 1913, Appendix II.

16 See Pickstone, op. cit. (13); Alison Kraft and Samuel J.M.M. Alberti, “"Equal though different”: laboratories, museums and the institutional development of biology in late-Victorian Northern England', Studies in History and Philosophy of Biological and Biomedical Sciences (2003) 34, pp. 203-236.

17 Bruno J. Strasser, 'Laboratories, museums, and the comparative perspective: Alan A. Boyden's quest for objectivity in serological taxonomy, 1924-1962', Historical Studies in the Natural Sciences (2010) 40, pp. 149-182, 153. See also Strasser's two essays 'The experimenter's museum: GenBank, natural history, and the moral economies of biomedicine', Isis (2011) 102, pp. 60-96; and 'Collecting nature: practices, styles, and narratives', Osiris (2012) 27, pp. 303-330.

18 The term 'museum' in the late nineteenth century already had our modern connotation of a permanent single-building institution caring for cultural artefacts in perpetuity - but it also had a range of other meanings associated with temporary or non-institutional collections, as in the use of 'museum' in book titles. Between this general meaning - correlating roughly to 'collection' - and the more fixed institutional meaning that we are familiar with, 'museum' could refer to any systematically arranged collection within an institution that was not itself known as a museum. Hence many laboratories had working museums within them, of, for instance, dried or preserved specimens, or teaching models; hence too my usage here, for collections of historical objects within institutions not dedicated to history. For a typical modern statement of what a 'museum' is see the ICOM definition, at http://uk.icom.museum/about-us/icom-definition-of-a-museum, accessed 11 April 2019.

19 This, moreover, fits with what we know about the rather wide usage of the term 'museum' in the midnineteenth century; see Sophie Forgan, "“But indifferently lodged ...": perception and place in building for science in Victorian London', in Smith and Agar, op. cit. (3), pp. 195-215. 
facts from the fragile and complex materiality of experiment; the former involves the production of fragile and complex histories from the apparently stable materiality of science. Like many of the authors in this issue I draw a distinction between the persistence/demise of objects and the persistence/demise of collections (see especially the essays by Bangham, Curry, Porter and Roque). Objects can and do outlive collections, because the latter are ontologically distinct from the former: a collection is not itself a physical object, nor even an aggregate of physical objects. Rather it is the pattern of objects arranged in space, with 'pattern' used in the dual sense of something that exists through its reproductions, and something arranged in a particular way. A collection has meaning by virtue of the ways it is reproduced (catalogues, images, descriptions), and its arrangements (displays in showcases, objects in store). Borrowing from Annemarie Mol, we can say that collections are enacted - they are 'done' or constituted by acts of reproduction and arrangement. ${ }^{20}$

Because objects constitute or contribute to historical knowledge, the reproduction and arrangement of collections determine the kinds of history available to actors at different times. Both the collection and its attendant historiography are fragile. This is not to say, however, that the phenomenon of the 'museum in the lab' has gone away: the practice of hoarding of old material in laboratories persists to this day, and much remains to be learnt about the way scientists work with and conceive of their past and the history of their subjects, especially through the preservation of material culture. ${ }^{21}$ Yet the collections dealt with in the present essay were transient, and need to be understood in the specific institutional context in which they were amassed.

There are aspects of the historical conjuncture of the late nineteenth century that are specific and were not repeated afterwards. Laboratories were seen as natural repositories of the past precisely because they were spaces in which the future could be constructed. The scientific enterprise was both commemorative and forward-looking; the uncertainty of the future had to be grounded in a sense of history. ${ }^{22}$ The relative lack of contemporary institutions dedicated to the history of science is key to understanding the juxtaposition of history and novelty. ${ }^{23}$ In Cambridge, for example, there was no museum for the history of science until the middle of the twentieth century, and nationally the only

20 Annemarie Mol, The Body Multiple: Ontology in Medical Practice, Durham, NC: Duke University Press, p. viii.

21 See the essays collected in Nicholas Jardine and Lydia Wilson (eds.), Recent Material Heritage of the Sciences, special issue of Studies in the History and Philosophy of Science (2013) 44(4), especially Nicholas Jardine and Lydia Wilson, 'Introduction: recent material heritage of the sciences', pp. 632-633; Soraya Boudia and Sébastien Soubiran, 'Scientists and their cultural heritage: knowledge, politics and ambivalent relationships', pp. 643-651; Ad Maas, 'How to put a black box in a showcase: history of science museums and recent heritage', pp. 660-668.

22 This notion is explored in a number of articles by Simon Schaffer, for example 'Physics laboratories and the Victorian country house', op. cit. (3); 'Making up discovery', in Margaret A. Boden (ed.), Dimensions of Creativity, Cambridge, MA: MIT Press, 1994, pp. 13-51; 'Metrology, metrication, and Victorian values', in Bernard Lightman (ed.), Victorian Science in Context, Chicago: The University of Chicago Press, 1997, pp. 438-474.

23 See Anthony J. Turner, “"Paris, Amsterdam, London”: the collecting, trade and display of early scientific instruments, 1830-1930', in Peter de Clercq (ed.), Scientific Instruments: Originals and Imitations, Leiden: Museum Boerhaave, 2000, pp. 23-60; Anastasia Filippoupoliti, “'What a scene it was, that labyrinth of 
relevant museums were the British Museum and the South Kensington Museum (with the Science Museum emerging from the latter in 1909). ${ }^{24}$ From the 1850 s on the British Museum had been acquiring historical scientific instruments, but these were almost all early, decorative pieces. ${ }^{25}$ The South Kensington Museum presented a more substantial repository for scientific apparatus; ${ }^{26}$ however, historical materials in fact constituted a small proportion of the total holdings, with contemporary scientific instruments and (especially) industrial apparatus dominating. ${ }^{27}$ Laboratories were therefore amongst the few spaces in which the history of precision instrumentation and experimental inquiry could be represented. In Cambridge this made additional sense given that questions in the history and philosophy of science featured in the examination system - the Natural Sciences Tripos. ${ }^{28}$ The turn to history happens at specific moments in institution building - when space is contested, when financial pressures are great, and when research or teaching regimes change. ${ }^{29}$

The essay is presented in two parts. The first uses a 1936 exhibition of Cambridge's scientific relics as a jumping-off point to survey the range of historical practices in the various Cambridge laboratories. This panoramic approach is intended to show the variety and complexity of pasts that scientists used objects to conjure in the years prior to the exhibition. With very few exceptions, historians have assumed that scientists' conceptions of the past are straightforward - narrowly progressivist and celebratory ignoring complex relationships between tragedy and celebration, pure and applied science, teaching and research, iconography and materiality. Commerce and commemoration are two key themes that emerge in my analysis. The second part turns to the Cavendish to explore the highly specific senses of time and memorialization at play in the early years of the laboratory (c.1874-1910), and the way these were transformed over the subsequent generations leading up to the 1936 moment. The key figure here

strange relics of science": attitudes towards collecting and circulating scientific instruments in nineteenthcentury England', Cultural History (2013) 2, pp. 16-37.

24 On Cambridge see James A. Bennett, 'The Cambridge legacy of Robert T. Gunther', in Willem D. Hackmann and Anthony J. Turner (eds.), Learning, Language and Invention: Essays Presented to Francis Maddison, Aldershot and Paris: Varorium and the Société internationale de l'astrolabe, 1994, pp. 78-83; Bennett, 'Museums and the establishment of the history of science at Oxford and Cambridge', BJHS (1997) 30, pp. 29-46. On the Science Museum see Peter J.T. Morris (ed.), Science for the Nation: Perspectives on the History of the Science Museum, Basingstoke: Palgrave Macmillan, 2010.

25 See Robert Anderson, 'Connoisseurship, pedagogy or antiquarianism? What were instruments doing in the nineteenth-century national collections in Great Britain?', Journal of the History of Collections (1995) 7, pp. 211-225.

26 See Robert Bud, 'Responding to stories: the 1876 Loan Collection of Scientific Apparatus and the Science Museum', Science Museum Group Journal (2014) 1, at http://dx.doi.org/10.15180/140104, accessed 2 January 2019.

27 See [anon.], 'The science collections at South Kensington', Nature (1889) 40, pp. 425-428. See also Robert Bud, 'Infected by the bacillus of science: the explosion of South Kensington', in Morris, op. cit. (24), pp. 11-40.

28 Details of the role of history and philosophy in the Natural Science Tripos examinations can be found in the University Registry guard book CUR 28.9, 'Natural Sciences Tripos', University of Cambridge Archives, Cambridge University Library.

29 A similar argument, but for contemporary collecting within labs, is made by Boudia and Soubiran, op. cit. (21). 
is James Clerk Maxwell, whose turn to history involved a mix of antiquarianism and modernism. The collection of historic instruments he acquired was rich and varied, and was related to the specifically historical nature of work on standards of measurement. Metrology, I argue, is an inherently historical form of scientific practice, as it relies on specific instruments in particular places, and these need to be preserved in order for the system of standards to persist; there is no clear boundary between this necessity and a deeper interest in the history of metrological science. In conclusion I attempt to characterize the meanings and significances of 'the museum in the lab', a phenomenon that ought to be understood in terms of the wide range of 'collections' present in laboratory spaces.

\section{Looking back from 1936}

In 1936, under the sponsorship of the Cambridge Philosophical Society, an exhibition of 'Historic Scientific Apparatus' was held in the university's ancient administrative buildings, known as the 'Old Schools'. Around two hundred artefacts illustrative of the history of science were on show - from astrolabes to zoetropes - dating from the thirteenth century to the 1920 s (Figure 1). ${ }^{30}$ These instruments, models, manuscripts and images had been gathered up from Cambridge's myriad institutions - its colleges, laboratories, museums - as well as from individual collectors and a handful of other sources. The exhibition had been instigated and largely organized by the historian Robert Gunther, forming a natural counterpart to similar labours at the University of Oxford. ${ }^{31}$

The 1936 Cambridge Old Schools exhibition was an important moment in the institutional trajectory of history of science in the United Kingdom. ${ }^{32}$ It formed a natural counterpart to the first series of lectures in the history of science at the university, ${ }^{33}$ and it was the spur for Robert Stewart Whipple's 1944 donation of two thousand historic instruments and books, which marks the origin of the Whipple Museum of the History of Science, from which Cambridge's Department of History and Philosophy of Science developed. ${ }^{34}$ In this sense, 1936 was a conciliatory and creative moment: the point of

30 The earliest object was a 'Steel-yard globe weight', c.1300, loaned from the Archaeological Museum; the latest was a micromanipulator, c.1922, from Biochemistry; see [Robert T. Gunther], Catalogue of a Loan Exhibition of Historic Scientific Apparatus in Cambridge; Arranged under the Auspices of the Cambridge Philosophical Society in the East Room of the Old Schools 8-23 June 1936, Oxford: Oxford University Press, 1936, pp. [5], 31. Astrolabes were loaned from Caius College, King's College, the Archaeological Museum and Prof. Newall; the zoetrope had been James Clerk Maxwell's and was loaned by the Cavendish Laboratory.

31 See Bennett's two essays, op. cit. (24); A.V. Simcock (ed.), Robert T. Gunther and the Old Ashmolean, Oxford: Museum of the History of Science, 1985; Robert Fox, 'The history of science, medicine and technology at Oxford', Notes and Records of the Royal Society (2006) 60, pp. 69-83.

32 See Anna-K. Mayer, 'Setting up a discipline: conflicting agendas of the Cambridge History of Science Committee, 1936-1950', Studies in History and Philosophy of Science (2000) 31, pp. 665-89, esp. $671 \mathrm{ff}$.

33 Published as Joseph Needham and Walter Pagel (eds.), Background to Modern Science: Ten Lectures at Cambridge Arranged by the History of Science Committee, 1936, New York and Cambridge: Macmillan and Cambridge University Press, 1938.

34 On the history of the Whipple see Liba Taub and Frances Willmoth (eds.), The Whipple Museum of the History of Science: Instruments and Interpretations, Cambridge: Cambridge University Press, 2006; and 


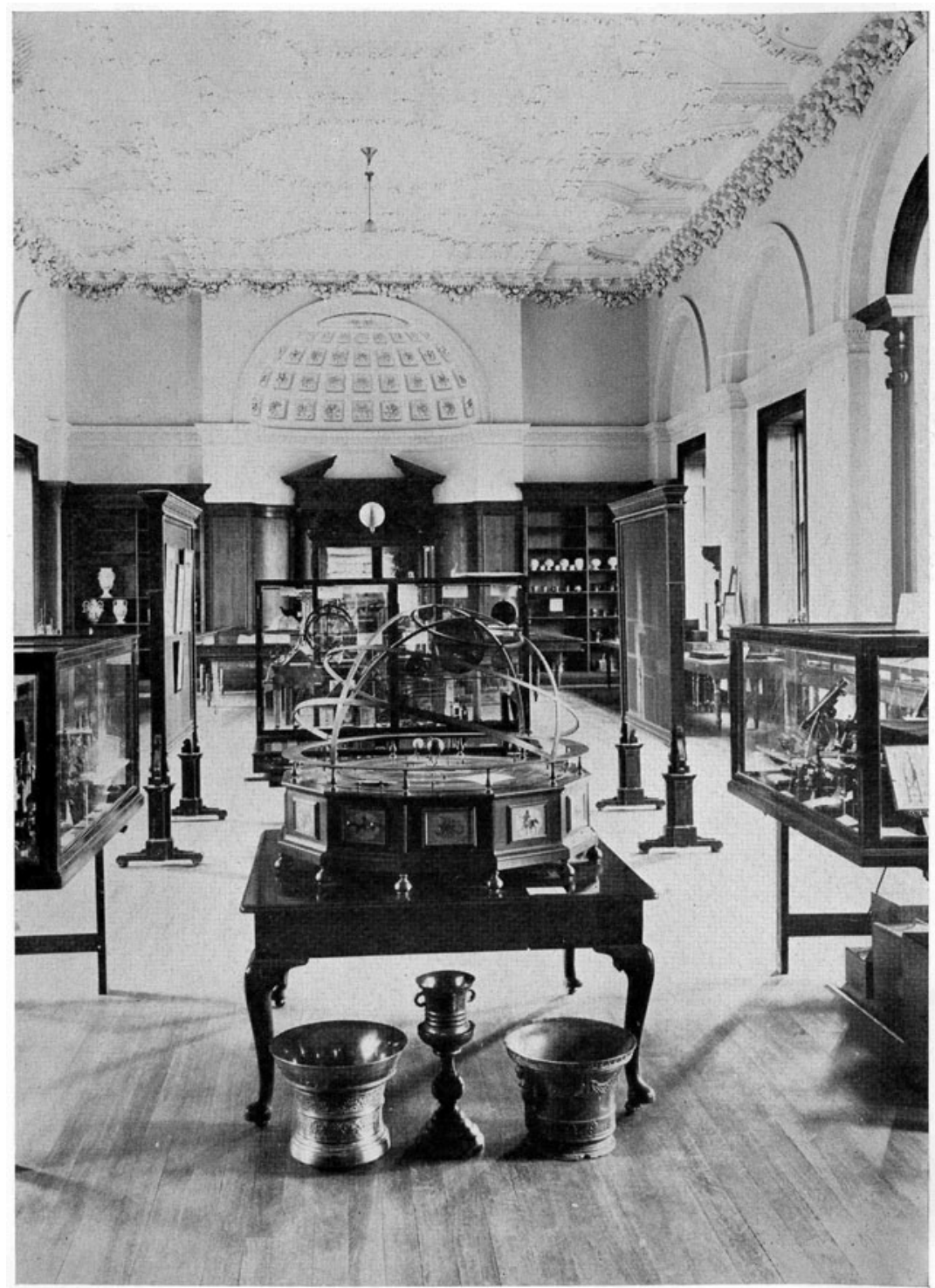

THE EXHIBITION OF HISTORIC SCIENTIFIC APPARATUS IN THE OLD SCHOOLS, JUNE I936

Figure 1. 'The Exhibition of Historic Scientific Apparatus' held in the Old Schools of the University of Cambridge, 8-23 June 1936. In the foreground can be seen the 'Grand Orrery' which now forms the centrepiece of the Main Gallery of the Whipple Museum of the History of Science, University of Cambridge, inv. no Wh.1275. Weights and measures (foreground), pharmacy jars (background, left), and microscopes (display case, near right-hand side) can also be seen. More astronomical instruments are just visible in the display case behind the Grand Orrery. Frontispiece to Robert T. Gunther, Early Science in Cambridge, Oxford: Printed for the author at the University Press, 1937. 
origin of a whole tradition of historical reflection and material preservation. Indeed, the book that was quickly produced after the exhibition - Early Science in Cambridge remains a crucial guide to the relics of a pioneering age of scientific research. ${ }^{35}$

But another aspect of the exhibition has passed unnoticed: the evidence it provides of the historical consciousness of the Cambridge laboratories themselves. In addition to the treasures of the Cambridge colleges, Gunther and his Cambridge collaborators had managed to find a surprisingly rich seam of historically important apparatus in the many laboratories that occupied Cambridge's two central scientific sites: the New Museums Site and the Downing Site (Figure 2).

The New Museums Site was the first large-scale space used by the university for scientific lectures, collections and laboratories; the main suite of museums was opened in 1865. The Cavendish Laboratory (experimental physics) joined the museums just under a decade later, and more laboratories were built on the site well into the twentieth century. By the time of Gunther's exhibition in 1936 the laboratories threatened to engulf the original museums, and a new site had been opened across the road, to the south, called the 'Downing Site'.

The story of these two sites is superficially one of the unimpeded triumph of the one kind of scientific space over another, of the relentless 'rise of the laboratory' over the demise of the museum. ${ }^{36}$ Yet Gunther's findings suggest an alternative history, in which acts of collection, curation and display coexisted with the experimental sciences. To these complex scientific locales Gunther brought his tireless energy for hunting through cupboards and finding hidden treasures. The exhibition was in fact only one part in a long process of what Gunther called 'archaeological' research into the material relics of science. ${ }^{37}$ By far his most ambitious project was a materially focused survey of the history of science at the University of Oxford. The first volume of this collection of documents and other sources appeared in 1920 with the title Early Science in Oxford, and by the time of the 1936 exhibition in Cambridge Gunther had reached volume ten (of an eventual fourteen). A 1919 exhibition of Oxford's early scientific apparatus had also contributed to the founding of the Museum of the History of Science in $1924 .{ }^{38}$

Hence, when in 1934 he wrote to the Cambridge Philosophical Society, it was already with the intention of replicating that achievement, and with the underlying aim of the salvage and preservation of early instruments. ${ }^{39}$ The society's quick and enthusiastic response set in motion a series of surveys of Cambridge's labs and colleges. Gunther himself carried out a number of these research trips, and was assisted by a number of Cambridge scientists, including the botanist Hugh Hamshaw Thomas, physicist

Joshua Nall, Liba Taub and Frances Willmoth (eds.), The Whipple Museum of the History of Science: Objects and Investigations, to Celebrate the 75th Anniversary of R.S. Whipple's Gift to the University of Cambridge, Cambridge: Cambridge University Press, forthcoming 2019.

35 Robert T. Gunther, Early Science in Cambridge, Oxford: Printed for the author at the University Press, 1937.

36 See the two essays by Sviedrys, op. cit. (12).

37 Bennett, 'The Cambridge legacy of Robert T. Gunther', op. cit. (24), p. 79.

38 Simcock, op. cit. (31).

39 Bennett, 'Museums and the establishment of the history of science', op. cit. (24), pp. 31, 34. 


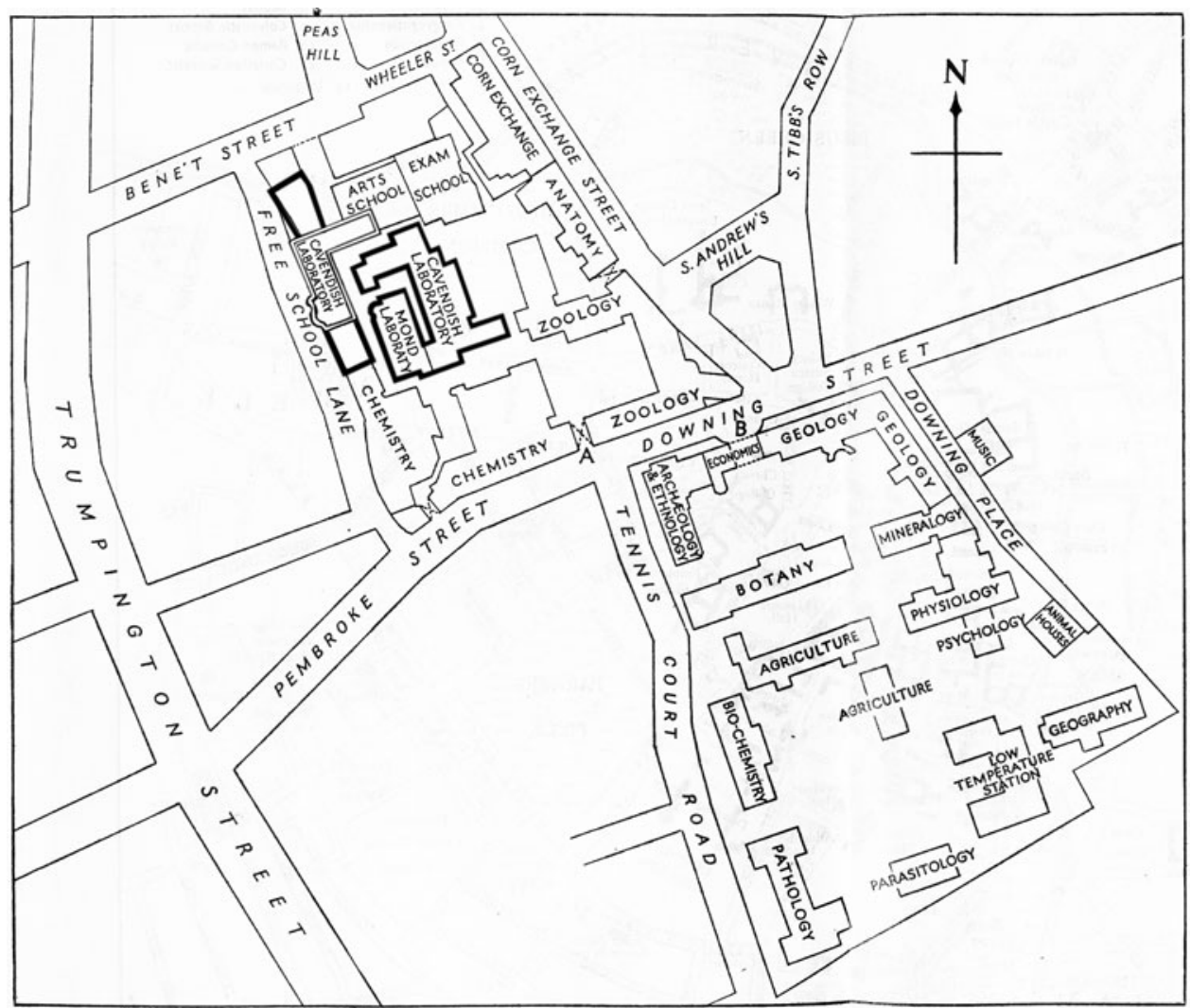

Figure 2. The New Museums Site (north) and Downing Site (south), at the time of the 1936 exhibition. From John Willis Clark, A Concise Guide to the Town and University of Cambridge, Cambridge: Bowes \& Bowes, 1936, opposite p. 136. The Cavendish Laboratory is marked in bold; the double line indicates the original (1874) building.

J.D. Cockcroft, mineralogist Arthur Hutchinson and astrophysicists F.J.M. Stratton and H.F. Newall. Between them this group identified the two hundred or so objects initially catalogued for the exhibition, along with well over a hundred further items of historic interest. ${ }^{40}$ The volume Early Science in Cambridge (ESC) contains the most comprehensive list of instruments put together by Gunther, extending to some 336 entries, in addition to other artefacts mentioned in passing in the text. Of these, more than half were preserved in Cambridge's laboratories. A breakdown by department of the number of objects can be seen in Table 1 .

Before turning to the objects themselves, it is important to note that the sense of history in new laboratories could be present in a number of ways not specifically tied to objects.

40 The ambiguity comes from the somewhat chaotic organization of Gunther's volume Early Science in Cambridge, which intersperses a revised exhibition catalogue throughout a series of historical narratives, arranged by subject; but the catalogue contains many more objects. Some of these must have been lent, but some cannot have been, because they are described by Gunther as 'lost' objects. 
Table 1. Distribution of objects at the 1936 exhibition.

Department/laboratory

Botany School

Biochemistry

Cavendish Laboratory (Physics)

Engineering Laboratory

Mineralogy (laboratory and museum)

Physiology

Solar physics

Zoological Laboratory

Number of objects listed in ESC

11

2

88

5

17

2

8

44

For example, on the south-west corner of the Chemical Laboratory, built on the New Museums Site, 1885-1889, was placed a carved plaque showing the family crests of Francis Bacon (1561-1626), Isaac Newton (1642-1727[NS]), William Hyde Wollaston (1766-1828), and J.F.W. Herschel (1792-1871), thus offering a gentlemanly and Cambridge-centric history of science. The Department of Biochemistry - in 1936 still a new discipline, and featuring only two objects in ESC - also had a keen sense of its past, albeit a more cosmopolitan one. Its monumental laboratory, built in 1924, contained within its library four wood carvings illustrating the unification of biology and chemistry in the personages of John Mayow (1641-1679), Thomas Graham (18051869), Justus Liebig (1803-1873) and Louis Pasteur (1822-1895). These were chosen by the laboratory's director, Frederick Gowland Hopkins, an 'evangelist' for the synthetic discipline of biochemistry who carefully used history in the construction of his 'modernist' stance. ${ }^{41}$ Another striking instance is Parasitology - another synthetic and even avant-garde discipline in interwar Cambridge. Here, again, the historical sensibility was iconographic: the director of Parasitology was G.H.F. Nuttall, and by the time of the lab's opening in 1922 he had amassed some three hundred portraits 'of those who have distinguished themselves in the domain of parasitology'. These were 'mostly framed and hung chiefly in the well-lit corridors, the grouping being by nations and as far as possible by subjects' ${ }^{42}$ This is an indication that even new and forward-looking institutions could be visibly tied to the past. ${ }^{43}$

There are, however, differences between this kind of iconographic historical sensibility and the collection of apparatus and the acquisition of old instruments. The most obvious point to make is that with portraits and other iconographic representations it is possible to select forefathers from all of history, but the materials found within a laboratory - or

41 See Harmke Kamminga and Mark W. Weatherall, 'The making of a biochemist I: Frederick Gowland Hopkins' construction of dynamic biochemistry', Medical History (1996) 40, pp. 269-292, $287 \mathrm{ff}$.

42 George H.F. Nuttall, 'The Molteno Institute for Research in Parasitology, University of Cambridge, with an account of how it came to be founded', Parasitology (1922) 14, pp. 97-126, 123.

43 For further reflections on historical practice, and especially portraiture, in institution building see Ludmilla Jordanova, Defining Features: Scientific and Medical Portraits, 1660-2000, London: Reaktion Books, 2000; and Jordanova, 'Institutions, identities and historical practices in science and medicine', STS Occasional Papers no 6 (2018), at www.ucl.ac.uk/sts/file/8371, accessed 10 April 2019. 
even those that can be acquired from outside - will tend to be unmistakably local, purely random or even insignificant. Turning to Table 1, and Gunther's 1936 exhibition, the pattern that emerges from the instruments that had been preserved in Cambridge's laboratories is of a predominance of objects commemorating some important figure or achievement in the history of the laboratory, and (often related to these) objects consolidating a style of instrumental work through the history of developments in a particular piece of apparatus.

The first category - objects of commemoration - is perhaps the least surprising and most numerous. The Victorian period is well known for the interconnection of its practices of commemoration and material accumulation; the culture of souvenir collecting, based on a generalized ideal of the Grand Tour, is one instance of this. ${ }^{44}$ An exemplary object in this category is Charles Darwin's large achromatic microscope (no 308 in ESC), held at the Botany School, where it had been deposited by Darwin's son Francis. As early as 1909 - the centenary of Darwin's birth - the Botany School had been prominent in the celebration of a scientist who in fact only had an institutional connection to Christ's College, Cambridge. Other famous scientists commemorated by the preservation of their instruments and artefacts included Samuel Pepys (objects at Magdelene College, no 107 in ESC), Isaac Newton (Trinity College, no 172 in ESC) and Adam Sedgwick (Sedgwick Memorial Museum [geology], p. 445 in ESC).

A special instance of commemoration is found in the Zoological Laboratory, which suffered a tragedy at the time of its opening, when Francis Maitland Balfour, the first Cambridge professor of comparative morphology, died in a mountaineering accident. Balfour, though now relatively little known in the history of biology, was, at the time of his death in 1882 at the age of thirty-one, considered a natural successor to Charles Darwin and a leader of the field of experimental embryology. As Helen Blackman has shown, Balfour's death caused a rupture not only in the institutional development of the Zoological Laboratory, but in the moral code of Victorian Cambridge. ${ }^{45}$ In the Zoological Laboratory Balfour's life's work was illustrated by a collection of his microscopes that had been passed down by subsequent holders of the professorship of comparative morphology. At first these microscopes had been given to Balfour's successor, Adam Sedgwick, presumably owing to their utility; later the collection as added to, and by 1936 it is possible to reconstruct the development of his career through the microscope collection, from his studies as an undergraduate to his fieldwork at the Naples Zoological Station and his mature researches into the development of the vertebrae in sharks and rays. ${ }^{46}$

In the comparison of Balfour to Darwin, the obsession with his interrupted career, and the material relics used to commemorate him, we can see some of the ways in which the new Cambridge School of Animal Morphology was consolidated and constructed within

44 See, for example, Marius Kwint, 'Commemoration and material culture', Journal of Victorian Culture (2005) 10, pp. 96-100.

45 Helen J. Blackman, 'A spiritual leader? Cambridge zoology, mountaineering and the death of F.M. Balfour', Studies in History and Philosophy of Biology and Biomedical Sciences (2004) 35, pp. 93-117. 46 See Gunther, op. cit. (35), pp. 366. 
the wider scientific community. ${ }^{47}$ The status of the microscope itself is by no means incidental to this process. This is dramatically illustrated in the following testimony from a Cambridge classicist, quoted at length owing to the way in which it ties a vision of science to a vision of gentlemanly conduct, spatially located and bound up with instrumental practice:

I shall never forget the day when I first saw Professor Balfour. I was being taken over the New Museums by a Science friend, and I was feeling very gloomy, for I was thinking to myself, 'After all, these new and ugly buildings are not Cambridge - not the old, true Cambridge. They are but an overgrowth, an excrescence of the real place.' At last we came to Balfour's laboratory, and there the Master was pointed out to me bending over a microscope, and surrounded by his pupils ... And as I saw those men listening to his words, and working by his side, I felt that they had realised, as few men in Cambridge ever do, the true ideal of University life. ${ }^{48}$

Here the sense of charisma and inspiration is combined easily with the pre-eminence of the microscope as a symbol of disinterested investigation - the typical scientific portrait of the time is of a scientist who has turned away from their work at the microscope and is now looking to the camera. ${ }^{49}$ Balfour's microscopes could stand in for the Zoological Laboratory's lost founding father.

The feature that emerges most clearly from the case of Balfour is the image of disinterested inquiry, with the microscope as its symbol. This is the key to the cultivation of the self-image of the scientist in this period, and is present in the other significant class of historical objects used in the construction of institutional identity: instruments that came to be identified with the research style of a particular lab. Of these, the most distinctive subset are prototypes of instruments that were to go into commercial production. These constituted a large proportion of instruments contributed to the 1936 exhibition by the biological departments. Zoology again provides a good example: the department had played an important role in the development of the microtome, a device permitting regular thin sections to be cut for microscopic work that simultaneously became a standard laboratory tool and permitted standard microscope preparations to be made. The best-known of these was the 'Caldwell-Threlfall microtome', which allowed 'ribbon sections' to be cut by a repeated action of the blade. ${ }^{50}$ This device had been invented by W.H. Caldwell and Richard Threlfall in 1882, and was a precursor of the commercially successful 'rocking microtome' also developed in Cambridge, by Horace Darwin, in $1885 .{ }^{51}$ The status of these academic-commercial collaborations in Cambridge and elsewhere in the late nineteenth century is a large and

47 See Helen J. Blackman, 'The natural sciences and the development of animal morphology in lateVictorian Cambridge', Journal of the History of Biology (2007) 40, pp. 71-108.

48 Quoted in Blackman, op. cit. (45), pp. 114-115.

49 On the pre-eminence of the microscope as a tool see Graeme Gooday, "Nature" in the laboratory: domestication and discipline with the microscope in Victorian life science', BJHS 24 (1991), pp. 307-341. On the microscope and iconography see, for example, W.J. Clark, 'The iconography of gender in Thomas Eakins portraiture', American Studies (1991) 32, pp. 5-28, 13.

50 See Nick Hopwood, "Giving body" to embryos: modeling, mechanism, and the microtome in late nineteenth-century anatomy', Isis (1999) 90, pp. 462-496.

51 A useful account was given by Sir Richard Threlfall himself in 1930: 'The origin of the automatic microtome', Biological Reviews (1930) 5, pp. 357-361. 
under-studied subject: there was striking crossover into industry, in particular in the formation of the Cambridge Scientific Instrument Company, which profited from its close connection with Cambridge's laboratories. ${ }^{52}$ The preservation in the Zoological Laboratory of the prototype Caldwell-Threlfall microtome represents the university side of the equation, which involved a careful rhetoric of scientific purity, even as devices were exported around the world, solidifying Cambridge's reputation through commercial means. Richard Threlfall made the case for purity later:

I am sometimes asked why I did not patent the machine. The answer is that, as it was a machine for the furtherance of scientific research and had no commercial application, both Caldwell and I considered that to take out a patent would have been as improper as it would be for a physician to patent a medical discovery. ${ }^{53}$

In addition to the self-effacing tone struck by Threlfall, his account consolidates the collegial self-fashioning of Cambridge science in this period, again with an emphasis on spatial relations. It was the proximity of the Engineering Department and the Zoological Laboratory that allowed Threlfall, a demonstrator in physics at the Cavendish, to improve upon Caldwell's initial designs and bring the new instrument to market. This culture of the sharing of skills, and collaboration over the small distances of the New Museums and Downing Sites, was successfully showcased in the display in 1936 of a wide array of instruments, many of which were commercialized by the Cambridge Scientific Instrument Company.

All of the trends examined here - iconography, commemoration and the preservation of specific instrumental lineages - were also present in the Cavendish Laboratory. But, as we have already seen, Maxwell's collecting went beyond these parochial celebratory themes. In the following section I offer an account of the underlying rationale of the Cavendish's early collections, before showing the ways in which these were subsequently undermined, to the point where, by 1936, only traces of the original impetus to collection remained.

\section{James Clerk Maxwell: the modernist as antiquarian}

As is clear from Table 1 above, the Cavendish Laboratory was a prodigious hoarder of old material. By the time of the 1936 exhibition the lab was under the direction of Ernest Rutherford, and was considered to be one of the pre-eminent centres of experimental physics in the world. Ever since the work of its third director, J.J. Thomson, the Cavendish had been famed for its investigations into atomic structure; its self-styled annus mirabilis had come in 1932, when the atom was split by artificial means by E.T.S. Walton and J.D. Cockcroft, and the neutron was discovered by James Chadwick. ${ }^{54}$ By the end of the 1930s, these and other developments led to a situation

52 M.J.G. Cattermole and A.F. Wolfe, Horace Darwin's Shop: A History of the Cambridge Scientific Instrument Company, 1878-1968, Bristol: Adam Hilger, 1987.

53 Threlfall, op. cit. (51), p. 361.

54 There is an extensive literature dedicated to the history of the Cavendish. In addition to the work of Schaffer, op. cit. (3); and Sviedrys, opera cit. (12); I have found the following particularly useful: 
in which new large-scale apparatus was required, putting ever more pressure on the Cavendish's limited space. This thought may well have been at the back of Rutherford's mind when he used the opening of the 1936 exhibition to call for the establishment of a permanent home for historical material associated with Cambridge research: his own lab ought to be filled with more urgently needed apparatus. ${ }^{55} \mathrm{In}$ this way 1936 was a pivotal moment, in which Maxwell's original idea, of a laboratory that was also a repository for historical material, was finally jettisoned.

We have already seen the enthusiasm with which Maxwell acquired antique scientific apparatus, but there were also practical and philosophical propositions involved in this collection. Maxwell was a Cambridge-trained mathematical physicist, who had spent the most productive years of his career at University College London. ${ }^{56}$ Although he was effectively brought out of retirement to head the Cavendish, he was only fortythree years old at the time of its opening. In his preparations for the construction and opening of the laboratory Maxwell undertook three major tasks: the first was to clear the way administratively for the acceptance of this new and controversial institution; the second was to determine the correct layout of a physics laboratory; the third was to ensure that it would be fully stocked with equipment. ${ }^{57}$

Above we saw that in just the second report on the activities of the laboratory, presented to the University Senate on 20 May 1876, Maxwell explained that a large collection of historical apparatus had been donated to the laboratory by H.W. Elphinstone, and that most of the collection had belonged to the physicist-chemist William Hyde Wollaston. ${ }^{58}$ The 'Wollaston Collection', as it came to be known, contained around a hundred separate pieces of apparatus. Many of these were to be exhibited much later at the 1936 exhibition, and some are now held at the Whipple Museum of the History of Science. But in 1876 when they arrived at the Cavendish they constituted a large part of its total store of material. The list contains many intriguing entries, amongst them the revolutionary platinum press used by Wollaston; an example of the earliest form of slide rule, called the 'circles of proportion' (dating from c.1635); and

T.C. Fitzpatrick et al., A History of the Cavendish Laboratory, 1871-1910, London: Longmans, Green, and Co., 1910; J.G. Crowther, The Cavendish Laboratory, 1874-1974, New York: Science History Publications, 1974; Jeff Hughes, 'Plasticine and valves: industry, instrumentation and the emergence of nuclear physics', in Jean-Paul Gaudillière and Ilana Löwy, The Invisible Industrialist: Manufactures and the Construction of Scientific Knowledge, Basingstoke: Macmillan, 1998, pp. 58-101; Dong-Won Kim, Leadership and Creativity: A History of the Cavendish Laboratory, 1871-1919, Dordrecht: Kluwer, 2002; Isobel Falconer, 'Cambridge and building the Cavendish Laboratory', in Raymond Flood, Mark McCartney and Andrew Whitaker (eds.), James Clerk Maxwell: Perspectives on His Life and Work, Oxford: Oxford University Press, 2014, pp. 67-[98]; Malcolm Longair, Maxwell's Enduring Legacy: A Scientific History of the Cavendish Laboratory, Cambridge: Cambridge University Press, 2016. On the construction of 1932 as a key year in the history of physics see Jeff Hughes, '1932: the annus mirabilis of nuclear physics?', Physics World (2000) 13, pp. 43-48.

55 See Bennett, 'Museums and the establishment of the history of science', op. cit. (24), p. 34.

56 For an outline of Maxwell's career see Simon Schaffer, 'James Clerk Maxwell', in Peter Harman and Simon Mitton (eds.), Cambridge Scientific Minds, Cambridge: Cambridge University Press, 2002, pp. 123-140.

57 See Falconer, op. cit. (54).

58 Harman, op. cit. (4), vol. 3, p. 337. 
a host of other miscellaneous instruments. The dominant themes of the collection are industrial chemistry and the history of precision calculation instruments.

One motivation for the acquisition might simply have been Maxwell's uncertainty over his ability to populate the new laboratory with apparatus. For this he had to do a number of things simultaneously: petition the laboratory's backer, the Duke of Devonshire, for funds; establish what kind of apparatus he would need; source the equipment from instrument-makers; and, ultimately, set up a flexible system in which instruments could be made in the lab, and exchanged with other institutions at home and abroad. ${ }^{59}$ A collection like the one donated by Elphinstone could be immensely valuable for the resolutely ahistorical process of 'cannibalization', in which parts of instruments were utilized, recombined and built into demonstration or experimental set-ups. ${ }^{60}$ Hence, looking more carefully at Maxwell's phrasing when he reported the donation, we can see that while 'most' pieces in the collection had belonged to Wollaston, and 'many' were 'of historical interest', some clearly fell into neither category. Prisms, micrometers, balances, thermometers and tripods could be used by students in the lab (though the item listed as 'Locked box without key' was perhaps not so useful). ${ }^{61}$ But utility can only take us so far in understanding the acquisition of the Wollaston material. Clearly the association with Wollaston himself was central to its identity. This much was made clear when, almost immediately upon its deposit in the Cavendish, a number of pieces were sent to the 1876 Special Loan Exhibition in South Kensington, which exhibited contemporary instruments as well as 'objects of historic interest from museums and private cabinets, where they are treasured as sacred relics'. ${ }^{62}$ This was a demonstrably 'historical' collection, and in order to understand its precise historical meaning for Maxwell and his contemporaries it is necessary to understand the kind of space it inhabited, namely a new physical laboratory built on a site populated with a range of museums.

When Maxwell came to Cambridge to take up the post as head of the Cavendish the dominant method for scientific teaching and research was the systematic collection of objects arranged for public display. ${ }^{63}$ Moreover, this was in no way limited to natural history, but extended to the physical sciences. Scientific collections and museums at Cambridge pre-dated the formal examination structure (the Natural Sciences Tripos)

59 On the acquisition and management of instruments in the early Cavendish see Falconer, op. cit. (54).

60 'Cannibalization' remains an under-studied practice. It is well known from anecdotes of working scientists; see, for example, the interview with former head of the Cavendish A.B. Pippard, published as 'Sizing up the Fermi surface: Brian Pippard speaks of metals, methods, and songs', MRS Bulletin (1999) 24, pp. 50-53. Attention to cannabilization has recently been given by those involved in scientific heritage; see the contributions to Jardine and Wilson, Recent Material Heritage of the Sciences, op. cit. (21). For an attempt to bring historians' attention to this issue see Simon Schaffer, 'Easily cracked: scientific instruments in states of disrepair', Isis (2011) 102, pp. 706-717.

61 Harman, op. cit. (4), vol. 3, p. 337.

62 See [Science and Art Department], Catalogue of the Special Loan Collection of Scientific Apparatus at the South Kensington Museum, 3rd edn, London: George E. Ayre and William Spottiswoode, 1877, pp. 57, 205, 567. Quotation from Anderson, op. cit. (25), p. 219.

63 Schaffer, op. cit. (3), pp. $155 \mathrm{ff}$. On the role of museums in university development in the nineteenth century see Sophie Forgan, 'The architecture of science and the idea of a university', Studies in History and Philosophy of Science (1989) 20, 405-434. 
that was introduced in $1851 .{ }^{64}$ Reform of teaching and the material provision of the sciences was to follow the 1852 Royal Commission report on 'the state, discipline and revenues of the University of Cambridge', singling out the lack of space for science as a major hindrance to the growth and role in national affairs of the university. Its recommendation, however, was that,

Besides museums containing collections of natural objects, or of such objects prepared for exhibition, and in addition to the apparatus provided for the material illustration of physical subjects in the way of experiments performed before a class, something further is requisite to enable the Student in his hours of private study to digest and utilize the knowledge he has gained at lectures and in reading. Nothing can be suggested having more immediate tendency in this direction than that he should have access [to] a museum of ... instruments, in which their construction may be contemplated and studied, and their peculiar contrivances and adaptations examined at leisure ... ${ }^{65}$

Nor was this at odds with the ideals of teaching at the time. In 1853 Robert Willis, Jacksonian Professor of Natural Philosophy, drew up a lengthy report on the nature of the projected scientific buildings. First he outlined what a scientific professor required his room for: demonstration and explanation through specimens, apparatus and drawings. He then described the nature of scientific buildings required for Cambridge:

A suite of Rooms, for the formation of a collection of Philosophical apparatus, should be provided to receive models, machinery, and apparatus of all kinds ... The University at present possesses no apparatus for physical or mechanical science, with the exception of that employed at the Observatory. In the Natural Sciences, collections have been formed and have become the property of the University, either by private gift or by purchase; and the University has from time to time erected Museums for the reception and display of such Collections, without which its members necessarily lose the advantages of studying them. ${ }^{66}$

Willis had powerful allies in his quest to extend the museological paradigm. As late as 1871 the physicist George Gabriel Stokes could write to the newly appointed Maxwell to inform him that 'the principal duty of the new professor in the first instance will be to give his advice as to the construction of the proposed physical laboratory and museum' ${ }^{67}$

The dynamic relationship between the laboratory and the museum was precisely the inverse of our modern notion of these two spaces. By the middle of the nineteenth century the museum was not just in the ascendency - it was the ideal type of scientific spatial organization. ${ }^{68}$ The museum was modernity: representing imperial expansion,

64 For collections and buildings see Carla Yanni, Nature's Museums: Victorian Science and the Architecture of Display, Baltimore: Johns Hopkins University Press, 2000, pp. 36-46. For teaching and institutional context see Peter Searby, A History of the University of Cambridge, vol. 3: 1750-1870, Cambridge: Cambridge University Press, 1997, Chapter 6.

65 [Cambridge University Commission], Report of Her Majesty's Commissioners Appointed to Inquire into the State, Discipline, Studies, and Revenues of the University and Colleges of Cambridge, London: W. Clowes and Son, 1852, p. 116, added emphasis.

66 Willis and Clark, op. cit. (14), vol. 3, p. 163, added emphasis.

67 Quoted in Schaffer, op. cit. (3), p. 158, added emphasis.

68 See Forgan, op. cit. (63). The literature on nineteenth-century museums is now vast; useful summary articles are Sally G. Kohlstedt, 'Museums: revisiting sites in the history of the natural sciences', Journal of the History of Biology (1995) 28, pp. 151-166; Mary P. Winsor, 'Museums', in Peter J. Bowler and John 
metropolitan science and disciplinary division. As Simon Schaffer has argued, in the absence of preconceived notions of what a laboratory was for, its promoters turned to the 'invention of tradition' to secure themselves against criticism or censure. ${ }^{69}$

In Cambridge this relationship was quite explicit: Robert Willis's designs for the 'new museums' were nothing if not new. In fact, in a tradition-bound university like Cambridge they were so radical that the scheme nearly didn't come off, a main line of argument against the museums being that they lacked ornament and were unduly functional. ${ }^{70}$ Unlike the museums, which were placed at the centre of the site, with no relation to its history, the Cavendish specifically preserved its spatial lineage: built on the site of a medieval friary, the laboratory preserved a Tudor doorway as the internal entrance. ${ }^{71}$ Having passed through heavy, gospel-inscribed wooden doors, under the statue of the Duke of Devonshire, this was the point of ingress.

Building on foundations of tradition, then, the Cavendish would reject the museum ideal, but only partially. Again, this can only be understood in terms of spatial arrangement. In planning the work of the laboratory, Maxwell conceived of an ascending scale: 'popular lectures and rough experiments for the masses; real experiments for real students; and laborious experiments for first-rate men'. ${ }^{72}$ In terms of laboratory layout, this required a large lecture room, an elementary laboratory and separate research rooms; in terms of equipment, it required demonstration apparatus, plenty of basic instruments and parts and the facilities for making and adapting more advanced pieces of research apparatus. It also entailed a small but profound shift in the spatial arrangement of scientific space. Maxwell changed the arrangement of rooms from the museum ideal of knowledge arranged systematically to the laboratory ideal of experiments arranged functionally:

We shall ... arrange our lectures according to the classification of the principal natural phenomena, such as heat, electricity, magnetism, and so on ... In the laboratory, on the other hand, the place of the different instruments will be determined by a classification according to methods, such as weighing and measuring, observations of time, optical and electrical methods of observation, and so on. ${ }^{73}$

So this was the particular kind of novelty involved in the Cavendish: the museum was repudiated by the arrangement of rooms by function rather than disciplinary

\footnotetext{
V. Pickstone (eds.), The Cambridge History of Science, vol. 6: The Modern Biological and Earth Sciences, Cambridge: Cambridge University Press, 2009, pp. 60-75; Samuel J.M.M. Alberti, 'The status of museums: authority, identity, and material culture', in David N. Livingstone and Charles W.J. Withers (eds.), Geographies of Nineteenth-Century Science, Chicago: The University of Chicago Press, 2011, pp. 51-72; Lukas Rieppel, 'Museums and botanical gardens', in Bernard Lightman (ed.), A Companion to the History of Science, Chichester: Wiley Blackwell, 2016, pp. 238-251. For an excellent recent survey, which is particularly sensitive to non-canonical museum spaces, see Carin Berkowitz and Bernard Lightman, Science Museums in Transition: Cultures of Display in Nineteenth-Century Britain and America, Pittsburgh: University of Pittsburgh Press, 2017.

69 See Schaffer, op. cit. (3); Schaffer, 'Metrology, metrication, and Victorian values', op. cit. (22).

70 See the debate transcribed in the Cambridge University Reporter, 15 March 1862.

71 Shipley, op. cit. (15), p. 301.

72 Quoted in Campbell and Garnett, op. cit. (1), p. 381.

73 Quoted in Fitzpatrick et al., op. cit. (54), p. 17.
} 


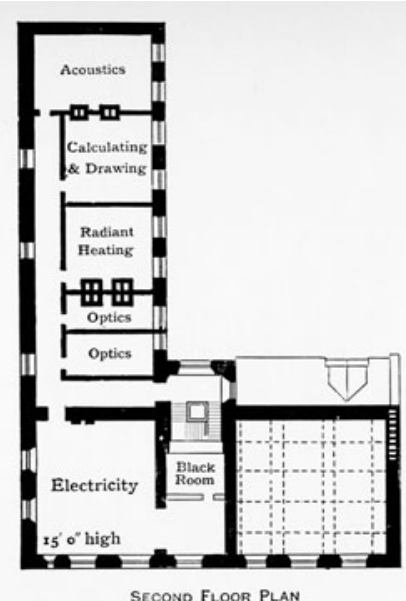

Second Floor PLAN

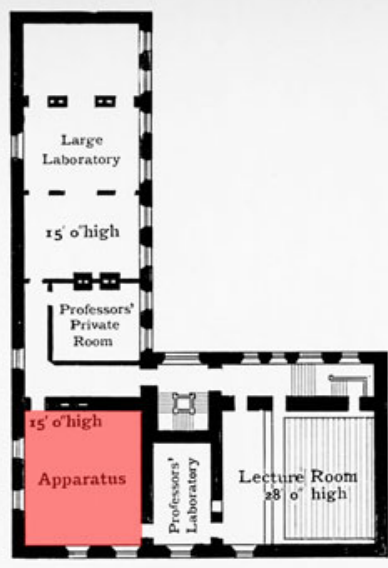

FIRST FLOOR PLAR.

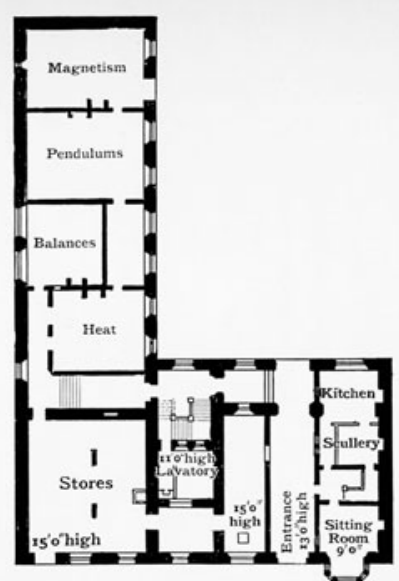

GROUnd PLAN.

PLAN OF ORIGINAL LABORATORY

Figure 3. Floor plan of the Cavendish at the time of its opening in 1874, showing the arrangement of rooms by instrument type. The shaded room in the first-floor plan is the 'Apparatus Room', which contained a number of large display cabinets housing contemporary and antique instruments; some of these display cabinets are preserved at the present-day museum of the Cavendish Laboratory.

subdivision. ${ }^{74}$ Yet the museum remained, through the idea of a store of apparatus systematically illustrating the subject developmentally, and through the presence of historical objects (Figure 3). The relation of history to modernity was complex, however: we can read the space of the Cavendish as a purposefully antiquated aesthetic performance that was nevertheless revolutionary in its arrangement of rooms, and we can see in the systematic and historical lists of instruments that Maxwell produced a remnant of the museological paradigm that dominated the New Museums Site and had informed the planning of the new laboratory.

In addition to these spatial complexities of time and memory, there is also a technical sense in which material accumulated in the laboratory was 'historical'. As early as 1871 , when Maxwell was contemplating the equipment needed in his lab in discussion with William Thomson, it was clear that the British Association for the Advancement of Science would transfer the material held by their Standards committee. ${ }^{75}$ In the first report on the activities of the Cavendish Laboratory, dated 27 April 1875, we find a listing of some thirteen 'Instruments belonging to the Committee of the British Association on Electrical Standards, deposited in the Laboratory'. ${ }^{76}$ Again the

74 For details of this development see Schaffer, op. cit. (3).

75 Harman, op. cit. (4), vol. 2, p. 627: 'We should get from the B.A. some of their apparatus for the Standard committee'. For details see Simon Schaffer, 'Late Victorian metrology and its instrumentation: a manufactory of Ohms', in Robert Bud and Susan E. Cozzens (eds.), Invisible Connections: Instruments, Institutions, and Science, Bellingham: SPIE Optical Engineering Press, 1992, pp. 23-56.

76 Harman, op. cit. (4), vol. 3, p. 213 
Cavendish here presents us with a strange mix of radical novelty and historicism. Standards of measurement are inherently historical insofar as they are arbitrary: metrology is a system in which the objects of measurement must be preserved so that the system can persist. ${ }^{77}$

By the 1870s, when the Cavendish was opened, the debate over the historicity of standards had reached fever pitch, with Maxwell's contemporary Charles Piazzi Smyth taking the radical position that all standards had been communicated by God to the Israelites, who had instantiated this knowledge in the Pyramids of Giza. ${ }^{78}$ Maxwell took an even more extreme historicist position, placing the origins of standards not in ancient Egypt but at the beginning of Creation, with the God-given establishment of 'molecular dimension'. As Maxwell put it, 'the foundation stones of the material universe remain unbroken and unworn' ${ }^{79}$ This reduced (or perhaps amplified) the work of finding true standards to the work of the physics laboratory: a place of precision measurement and calculation.

In a more pragmatic sense metrology is always historical: new instruments can only be calibrated against older instruments - though older here might refer to the very recent past. The point is that the instruments that make standard measurements have to exist in sequence, to be related to one another in a series. Hence even highly pragmatic textbooks like the Cavendish's own Practical Physics (1885) turned to history in order to introduce modern standards, and Maxwell and Fleeming Jenkin supplied a historical preamble to their technical appendix to the 1873 British Association for the Advancement of Science report on electrical standards appointed. ${ }^{80}$ This kind of attention to material survival shades into the history of metrology, in which Maxwell was intensely interested. This too relies on the material survival of instruments. In fact there is a very strong sense in which the history of metrology consists in the instruments themselves. To put it another way, at any given point, earlier work on standards can only have meaning if the apparatus used survives.

This explains the particular fervour of Maxwell's inquiries to P.G. Tait regarding the Florentine thermometer, quoted at the outset. The history of thermometry could only be understood if the material survived, and so the chance rediscovery in the 1820s of a group of the earliest thermometers provided a remarkable opportunity (Figure 4).

This is how Maxwell accounted for the instrument his 1871 textbook Theory of Heat:

77 Schaffer, 'Metrology, metrication, and Victorian values', op. cit. (22).

78 Schaffer, 'Metrology, metrication, and Victorian values', op. cit. (22), pp. 449-459; Eric M. Reisenauer, “"The battle of the standards": Great Pyramid metrology and British identity, 1859-1890', The Historian (2003) 65, pp. 931-978; Michael J. Barany, 'Great Pyramid metrology and the material politics of basalt', Spontaneous Generations: A Journal for the History and Philosophy of Science (2010) 4, pp. 45-60.

79 Quoted in Schaffer, 'Metrology, metrication, and Victorian values', op. cit. (22), p. 461.

80 R.T. Glazebrook and W.N. Shaw, Practical Physics, London: Longmans, Green and Co., 1885; James Clerk Maxwell and Fleeming Jenkin, 'On the elementary relations between electrical measurements', in William Thomson, James Prescott Joule, James Clerk Maxwell and Fleeming Jenkin (eds.), Reports of the Committee on Electrical Standards Appointed by the British Association for the Advancement of Science, London: E. and F.N. Spon, 1873, pp. 59-96. 


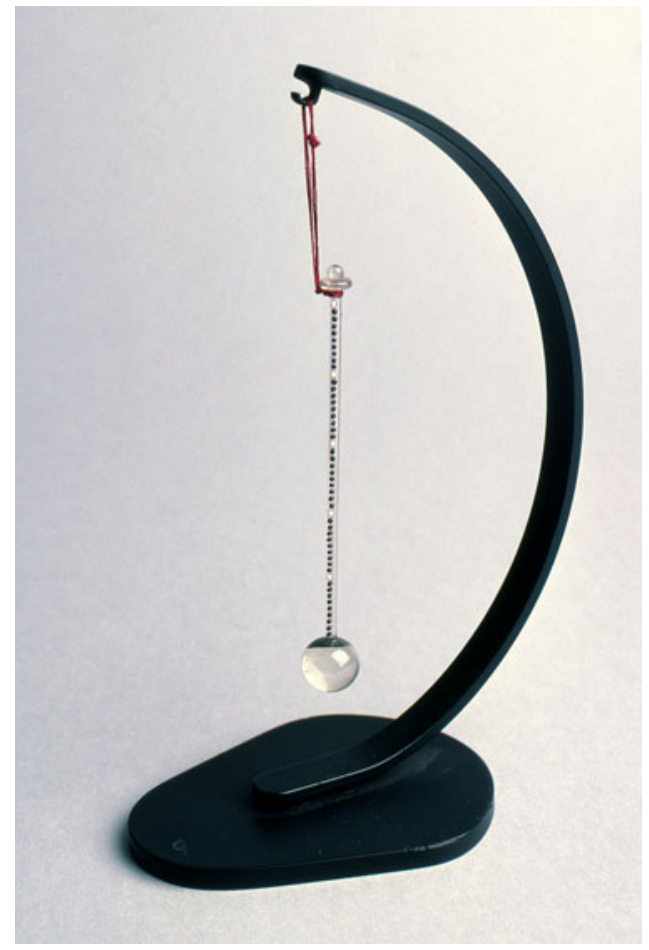

Figure 4. Florentine thermometer, c.1660. Whipple Museum of the History of Science, University of Cambridge, inv. no Wh.1116. the thermometer may be used to compare the temperature of any two bodies at the same time or at different times, so as to ascertain whether the temperature of one of them is higher or lower than that of the other ... For this purpose it would be necessary to carry the same thermometer to different places, and to preserve it with great care, for if it were destroyed and a new one made, we should have no certainty that the same temperature is indicated by the same reading in the two thermometers. Thus the observations of temperature recorded during sixteen years by Rinieri at Florence lost their scientific value after the suppression of the Accademia del Cimento and the supposed destruction of the therm2ometers with which the observations were made. ${ }^{81}$

By acquiring one of the thermometers Maxwell was restoring the 'scientific' value of earlier observations, and bridging the gap between his own lab's research and that of the very first generation to make systematic measurements of temperature. This is the most precise sense in which historical apparatus retained meaning in the Cavendish. Maxwell's was a technical collection - of the history of precision measurement and standardization - and it was

also a personal collection, full of his own earlier models and contraptions, and closely related to his historical researches into the electrical measurements made by Henry Cavendish in the eighteenth century. ${ }^{82}$ Within the collection, and in the way it related to other instruments in the laboratory, there is continuity with both the syllabus and research culture: while antique standards could be used in explaining the historically situated nature of all standards, models and other pieces of demonstration apparatus could be used in elementary lectures, and as provocations to further research. It is one of the characteristic features of Maxwell's work that simple model making was connected to some of the most advanced questions in Victorian physics. ${ }^{83}$

Physical questions were, for Maxwell, also typically questions of perception. In a late essay entitled 'Psychophysik' Maxwell asked whether there could be a true science of consciousness. His answer was that there could not - the Ego, he said, would always

81 Maxwell, op. cit. (10), p. 34.

82 Isobel Falconer, 'Editing Cavendish: Maxwell and The Electrical Researches of Henry Cavendish', at arxiv.org/abs/1504.07437, accessed 10 July 2018.

83 See Schaffer, op. cit. (56); Joshua Nall and Liba Taub, 'Three dimensional models', in Lightman, op. cit. (68), pp. 572-586. 
just fail to leave a material trace of itself. But, as a true skeptic, this led Maxwell to another kind of reflection, quoted in my epigraph, on just how much of human experience could be recorded and memorialized. ${ }^{84}$

The soul does not survive, Maxwell argued, but the self is an acting thing that leaves traces. This, too, was manifest in the lab in its physical collections. The instrument he used to illustrate this was an Edison phonograph, and he described the way it recorded and preserved the human voice, relating this to the body as a 'recording' device for the soul. For Maxwell, single objects could be used as provocations to philosophical, antimaterialist inquiry, in the manner of the older pairing of natural philosophy and natural theology. Continuity with modern physics was provided by the teleological history of precision measurement, which brought natural phenomena under the control and standardization of the experimenter. But Maxwell remained circumspect about the place of the soul in relation to natural inquiry: all phenomena were manifest as traces that could be compared and measured, but the soul itself transcended physical inquiry. The history of measurement was therefore connected to the culture of memorialization: both were physically manifest in objects, and science could not go beyond these material traces. 'Molecular dimension' itself could only be registered while the atoms remained unknowable; standards could only be compared; the soul could only leave traces. ${ }^{85}$ Just as Maxwell built the Cavendish laboratory in the image of his country home at Glenlair, so it was only proper that the Cavendish should be fitted out with objects of antiquarian interest. Yet antiquarianism, as many scholars have argued, was not only a gentlemanly pursuit but also a revolutionary activity: the use of the past in the creation of the future. ${ }^{86}$ It was in this sense that Maxwell's antiquarianism was part of his novel conception of the nature and role of physics as a subject of study.

After the opening of the Cavendish, however, Maxwell's own future was curtailed, and he did not have time to 'set up monuments' to his own achievements before his death, in 1879, at the age of forty-eight. The immediate task, for those who were closest to Maxwell, and who shared his scientific and institutional ideals, was to finish the job he had started; that is, to complete the programme of establishing electrical standards. This was achieved under the directorship of Lord Rayleigh, whose own instruments were to become legendary within the laboratory and are preserved to this day. ${ }^{87}$ Memorialization of Maxwell himself came quickly and in monumental form, when in 1882 two of his former students edited The Life of James Clerk Maxwell, and more subtly but materially through the display of Maxwell's teaching models and

84 Campbell and Garnett, op. cit. (1), p. 454.

85 See Falconer, op. cit. (54), p. 76: Maxwell's article 'Atom' in the Encyclopaedia Brittanica 'reviewed the problems of explaining mass and gravitation, repeating his view that while science was about the form of matter, its initial creation lay outside the realm of scientific explanation'.

86 See, for example, Peter N. Miller, 'A tentative morphology of European antiquarianism, 1500-2000', in Alain Schnapp (ed.), World Antiquarianism: Comparative Perspectives, Los Angeles: Getty Research Institute, 2014, pp. 67-87.

87 Schaffer, op. cit. (75). 
consolidation of the historical collections. Already, however, changes were afoot in the self-conception of the laboratory, and here again Maxwell's memory was to play a central role.

By the beginning of the twentieth century the Cavendish was entering its so-called 'golden age'. ${ }^{88}$ Specifically, the electrical-standards programme had been supplanted by a series of experimental researches instigated by J.J. Thomson, whose own speciality was the study of electrical discharges through gases, culminating in his discovery of the first subatomic particle, the electron. This important development in the transformation of the Cavendish was also, in part, articulated through the collection and display of material, in particular the combination of 'evolutionary' displays of apparatus and the practice of keeping relics of great experiments. By the time of the first historical account of the Cavendish Laboratory, in 1910, we can see the consolidation of the lab's sense of itself at work in a number of ways - some of which went specifically against the grain of Maxwell's own approach. For one thing, the history of the laboratory was now commemorative in one specific respect: it was not to be a history of 'what work was done, but of how that work came to be done'. Authors contributing to the volume were asked to demonstrate 'the evolution of the ideas which have inspired physical teaching and research in Cambridge, and the part played in that evolution by the many eminent men who have worked in the Laboratory'. ${ }^{89}$ This was in part in order to make the volume appealing to the general public. But it also served to separate out the key terms of the development of the lab: its underlying ethos, the role of 'eminent men' and the evolution of ideas.

In terms of the first of these, Maxwell could now play his role as founding father: his fundamental contribution had been the determination of the nature of the space of the laboratory, as a communal home for experimental science, in contrast to the isolated experiments that had gone on before him. Maxwell had not sought to perpetuate a research programme based on his own discoveries, according to the History, but had rather laid the groundwork for others to 'follow his own path'; that is, to learn to experiment and think like him, rather than with or against his ideas. ${ }^{90}$

The subtle transformation of Maxwell's founding genius was also effected later in the book through a transformation of the material that he had begun to collect in the $1870 \mathrm{~s}$. Chapter 8 of the 1910 History was written by Norman Campbell, a researcher at the Cavendish working primarily on radioactivity. By the time of the History Campbell was already a tyro within the physics community, having written a successful textbook, Modern Electrical Theory, which drew a sharp divide between the 'old' physics of mathematical analysis and the 'new' experimental physics of the Cavendish. In the History Campbell crossed the boundary between the two epochs with the help of an instrument, the electroscope, whose 'evolution' was depicted through a series of instruments going back to the early nineteenth century and culminating in the latest model invented in the Cavendish itself (Figure 5).

88 See in particular Kim, op. cit. (54).

89 Fitzpatrick et al., op. cit. (54), p. vi.

90 Fitzpatrick et al., op. cit. (54), p. 38. 


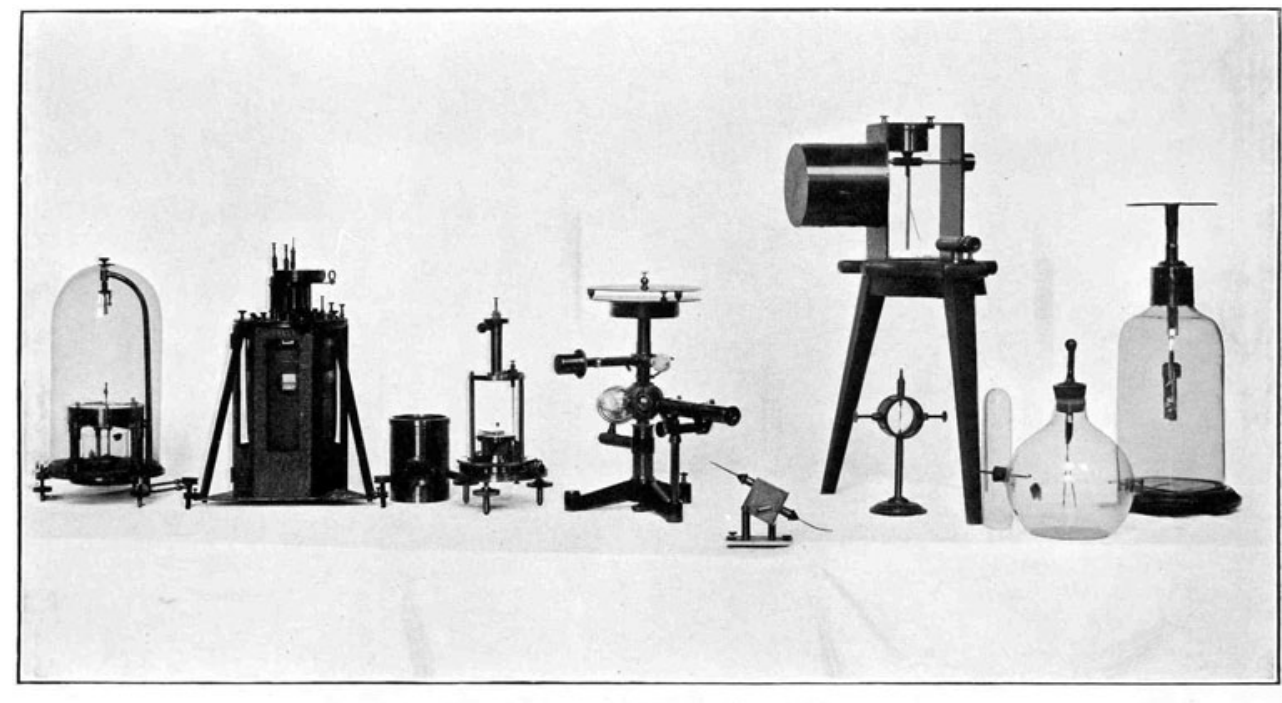

THE EVOLUTION OF THE ELECTROMETER

Figure 5. A display of electrometers, showing the development of the instrument, from T.C. Fitzpatrick et al., A History of the Cavendish Laboratory, 1871-1910, London: Longmans, Green, and Co., 1910, opposite p. 236.

Much of Campbell's chapter is dedicated to charting the specifically novel experimental work in the Cavendish - on the ionization of gases and radioactive phenomena. So it might seem strange for him to illustrate the evolution of an instrument that pre-dated these researches. But in showing continuity, Campbell was here involved in another iteration of the invention of the Cavendish tradition - the bid to show, by material means, that the new programme was legitimate precisely insofar as it was in fact tied to an experimental legacy. This was as much a model for research within the Cavendish as it was a programme for the standardization of laboratory practice elsewhere. Throughout the late nineteenth century the Cavendish worked closely with the Cambridge Scientific Instrument Company to develop standard lab apparatus. This coincided with the self-conscious construction of a laboratory-wide culture of making do with 'string and sealing wax'. ${ }^{91}$ It was precisely because the Cavendish had made itself independent of outside instrument-makers that it could promote designs based on its own prototypes with an outside instrument-maker (albeit one with close professional ties to the laboratory). Nowhere is this better summarized than in C.V. Boys's lecture on drawing fine quartz threads, which he concludes with the following exhortation:

91 See Kim, op. cit. (54), p. 84; but to see that this was originally a Victorian ideal compare Alexander Wood, The Cavendish Laboratory, Cambridge: Cambridge University Press, 1946, p. 18. For a deconstruction of the ideology as it was (mis)applied in the interwar period see Hughes, op. cit. (54). 
And now in conclusion, I would only say that if there is anything that is good in the experiments to which I have this evening directed your attention, experiments conducted largely with sticks and string and straw and sealing-wax, I may perhaps be pardoned if I express my conviction that in these days we are too apt to depart from the simple ways of our fathers, and instead of following them, to fall down and worship the brazen image which the instrument-maker hath set up..$^{92}$

But it was Boys himself who was central to the relationship between the Cavendish and the Cambridge Scientific Instrument Company, in particular through the marketing of his radiomicrometer. Hence the preservation of early versions of instruments that had gone into commercial production was a double celebration of the independence of the laboratory: it was independent from outside influence (and from the fees of instrument-makers) and independent as the arbiter of the kinds of instrument that laboratories would need in order to conduct researches similar to those carried out in Cambridge.

Further iterations of the Cavendish's attitude to historical material occurred in the 1930s, when the lab used its history as a fundraising tool and simultaneously advocated for the founding of a separate history-of-science museum, and after the Second World War, when the Whipple Museum was founded and the Cavendish itself set up a permanent display dedicated to the successive eras of its achievements. ${ }^{93}$ At each stage, the Cavendish fashioned its own image by preserving and discarding apparatus. Because of this iterative process it is rarely possible to say precisely when a piece of equipment or old instrument 'became' historical. As I argued at the outset, the relationship between objects, collections and historical memory is dynamic, and moments of historical awareness can just as easily be lost as conjured into existence.

As we have seen, very early in the life of the Cavendish, Maxwell acquired a large quantity of historical apparatus. Just as Maxwell looked forward to new developments in his fields, he also looked back to its history. His collection gestured to a relatively standard progressive historiography, to be sure, but it was also idiosyncratic in certain respects. It reached far beyond the confines of local or institutional history, it spoke to a certain materially bound concept of the history of physical standards, and it was a product of a Victorian interest in relics and memorials. ${ }^{94}$ But Maxwell's vision - of a museum within the laboratory, and the marriage of historicity and modernity - was ultimately undone. His collection ended, though it did so in stages: first with his death in 1872, again with the changing needs of the laboratory at the turn of the twentieth century, and then in the middle of the twentieth century, when a museum for the

92 C.V. Boys, 'Quartz fibres', in [various], Annual Report of the Board of Regents of the Smithsonian Institution, Showing the Operations, Expenditures, and Condition of the Institution to July, 1890, Washington, DC: Government Printing Office, 1891, pp. 315-334, 324.

93 These later relationships between the Cavendish and the Whipple have been explored in Tabitha Thomas [née Burden], 'Characterising collections: on the preservation of old scientific apparatus at the Cavendish Laboratory and the Whipple Museum, Cambridge', unpublished Part III dissertation, Department of History and Philosophy of Science, University of Cambridge.

94 On scientific relics see Rebekah Higgitt, 'Instruments and relics: the history and use of the Royal Society's object collections c.1850-1950', Journal for the History of Collections (2018), at https://academic.oup.com/ jhc/advance-article/doi/10.1093/jhc/fhy038/5144837, accessed 10 April 2019. 
history of science was proposed (1936) and eventually founded (1944-1951). ${ }^{95}$ This gradual process involved the removal of Maxwell's personality from the Cavendish, so that it could be replaced with his persona: the antiquarian philosopher of physics and its history was replaced by a noble founder, a discoverer, a modernist. To memorialize Maxwell, the Cavendish had to discard his museum. What Maxwell became in the eyes of his institutional descendants was as much a process of forgetting as it was of remembering.

\section{Conclusions}

As mentioned at the outset, history (or, perhaps better, 'historicity') within the experimental sciences is fragile and complex, and the meanings given to objects do not last unchanged. Historical understanding is hard to recover, was often temporary, and did not survive even if antique instruments remained. The Florentine thermometer so beloved of Maxwell was forgotten after his death, re-found by Gunther in preparation for his 1936 exhibition, forgotten again when the Cavendish set up a permanent museum display in the 1950s, and only finally found in the 1970s, when the Cavendish moved to a new location and the thermometer was transferred to the Whipple Museum of the History of Science, where it lives to this day. ${ }^{96}$ Many other objects in the Whipple Museum and other scientific collections have similar histories, though issues of scale mean that it is all but impossible to work backwards from a present collection to more than just a few of the previous collections it masks.

Underlying this instability, however, are two main historical trends: the growth of the institutional history of science and the increased professionalization of the laboratory. ${ }^{97}$ The former resulted in much material being transferred to museums, and expertise gradually shifting from scientists to historians; the latter demanded that collections within labs be closely focused on celebrating heroic figures or experiments, or consolidating instrumental practices and styles of research. ${ }^{98}$ These kinds of historical practice were determined by shifting concepts of space, and were particularly prominent at moments of change, with all of the economic consequences of the growth of the laboratory sciences in the late nineteenth and early twentieth centuries.

It remains to situate this study in relation to the historiography of the laboratory and museum, and the study of scientists' conceptions of history. Lorraine Daston has given a brief spatial analysis of the latter in her paper 'The sciences of the archive'. For Daston,

95 See Bennett's two essays, op. cit. (24).

96 For details of the 1974 move and its consequences for the Whipple collections see the papers in the Whipple Museum Archives, University of Cambridge, File Q, 'Handlist of items transferred from Cavendish Laboratory August/September 1974'; Thomas, op. cit. (93). On the move itself see Crowther, op. cit. (54), Chapter 32 .

97 For the former, see in particular Mayer, op. cit. (32); for the latter (in this context) see Sviedrys, opera cit. (12).

98 See the special issue of the Journal for the History of Collections entitled Shaping Scientific Instrument Collections (2018) (ed. Samuel J.M.M. Alberti), introduction at https://doi.org/10.1093/jhc/fhy046, accessed 10 April 2019; Samuel J.M.M. Alberti, 'Why collect science?', Journal of Conservation and Museum Studies (2017) 15, pp. 1-10. 
the site of memory in the laboratory is the library. ${ }^{99}$ One of Daston's case studies is the new (as of 1974) Cavendish Laboratory building, which was designed with a prominent and central library space. But thinking of history as primarily 'bookish' means that the laboratory's memory is necessarily spatially separate from its practical functions. Here I have argued that history and memory can be found scattered throughout the laboratory space, and that under pressure these senses of time deepen and become more visible. The key point is that collections of historical apparatus often overlapped with other kinds of 'collections': the array of experimental apparatus carefully curated by the lab technician or demonstrator, the jumble of apparatus kept for training or hoarded for parts, the systematic collection of training materials used in elementary instruction, the unsystematic collection of old apparatus used for the same purpose. This is distinct from, but related to, the kind of history that persists in the experimental sciences, according to Daston, namely that embodied in stockpiles of data, specimens, observations from the past and so on. ${ }^{100}$ The laboratory, in all these activities, is a space of accumulation, and of competing temporalities.

Finally, the question that looms over all discussions of the laboratory has to do with their special status as 'spaces apart'. Graeme Gooday has pointed out that the laboratory has enjoyed mixed historiographic fortunes in the last couple of decades. ${ }^{101}$ Histories of its 'rise' were first undermined in a way that redoubled its authority: i.e. micro-histories and sociological studies of 'laboratory life' were premised on the authority and separateness of the lab's spaces and systems of authorization. More recently, Gooday argues, the lab has come to be seen as, if anything, too special, and historical interest has turned to the museum, to the field, to discourse and popularization, to 'knowledge in transit' and so on. Gooday's response to this is that we preserve the lab while de-essentializing it, by looking at non-canonical laboratories, experiments in other spaces, and laboratories as just one part in the network of scientific credit and meaning-making. Laboratories, for Gooday, are 'interstitial entities, drawing their value and meaning from the people and institutions with which they were juxtaposed, opposed, and integrally networked'. ${ }^{102}$ My proposal is that by studying historical practice in the late nineteenthand early twentieth-century laboratory - as a practice not fully distinct from concepts of antiquarianism, memory and memorialization - we can see just such 'integral networks' that bind the laboratory to society. These are networks of affect, commerce and authority: the museum in the lab is the space where a form of sociable materiality can coexist with, augment and contrast with a form of (supposedly) asocial materiality. Typically this juxtaposition is interrogated from the outside in, as it were, from society to the laboratory - but my contention is that the inside of the laboratory was from the beginning already in dialogue with the exterior, though this exterior might just as well lie in the past or future as in the present.

99 Lorraine Daston, 'The sciences of the archive', Osiris (2012) 27, pp. 156-187.

100 For an expanded analysis of the 'sciences of the archive' see Lorraine Daston (ed.), Science in the Archives: Pasts, Presents, Futures, Chicago: The University of Chicago Press, 2017.

101 Graeme Gooday, 'Placing or replacing the laboratory in the history of science?', Isis (2008) 99, pp. 783-795.

102 Gooday, op. cit. (101), p. 786, original emphasis. 